\title{
Timing of commencement of maintenance dialysis and mortality in young and older adults in Singapore
}

\author{
Liang Feng ${ }^{1}$, Ai Zhen Jin², John Carson Allen ${ }^{3}$, Khuan Yew Chow ${ }^{4}$ and Tazeen Hasan Jafar ${ }^{1,5^{*}}$
}

\begin{abstract}
Background: The benefit of early dialysis initiation remains controversial with a paucity of data in Asians. Therefore, we undertook this study to investigate the association between timing of initiation of dialysis and mortality in Singapore.

Methods: The study used data from the Singapore Renal Registry database on 3286 patients with incident end-stage renal disease (ESRD) who commenced maintenance dialysis between January 2008 and December 2011. The data was further linked with the National Death Registry to acquire survival information until December 2013. We classified serum creatinine-based, estimated glomerular filtration rate (eGFR) by the Chronic Kidney Disease Epidemiology Collaboration (CKD-EPI) equation at the start of dialysis into 3 categories: Early $\left(\geq 10 \mathrm{ml} / \mathrm{min} / 1.73 \mathrm{~m}^{2}\right)$, intermediate ( 5 to $\left.<10 \mathrm{ml} / \mathrm{min} / 1.73 \mathrm{~m}^{2}\right)$ and late $\left(<5 \mathrm{ml} / \mathrm{min} / 1.73 \mathrm{~m}^{2}\right)$.
\end{abstract}

Results: In the unadjusted analysis, both early and intermediate dialysis initiation groups were at greater risk of death relative to late dialysis (Early: $H R=2.47$; Intermediate: $H R=1.54$ ). In the multivariate model, a significant interaction was detected between age and eGFR at dialysis initiation $(p=0.04)$. Adjusted mortality risk progressively increased with earlier initiation of dialysis for patients aged $18-54$ years $(p=0.006)$ and aged 55 to 64 years $(p<0.001)$, and no statistically significant difference was observed for patients aged 65 years or older $(p=0.12)$.

Conclusions: Early versus later initiation of dialysis was associated with significantly higher risk of mortality in Singapore's non-elderly population, and appeared to offer no survival advantage among the elderly.

Keywords: Dialysis initiation, Mortality, Glomerular filtration rate, Elderly

\section{Background}

End-stage renal disease (ESRD) is a global public health problem with over 2.6 million people on renal replacement therapy (RRT) of whom $>75 \%$ receive costly dialysis [1]. Singapore ranks among the top five countries with highest incidence of ESRD [2]. Worldwide use of RRT is projected to rise sharply to 7.6 million people by 2030 with the greatest increase in Asia.

In the past decade, a trend toward earlier initiation of dialysis at higher eGFR levels has been noted [3, 4]. In the United States, maintenance dialysis in patients with advanced chronic kidney disease (CKD) was initiated an

\footnotetext{
* Correspondence: tazeen.jafar@duke-nus.edu.sg

${ }^{1}$ Program in Health Services and Systems Research, Duke-NUS Medical

School, 8 College Road, Singapore 169857, Singapore

${ }^{5}$ Department of Renal Medicine, Singapore General Hospital, Singapore,

Singapore

Full list of author information is available at the end of the article
}

average of 147 days earlier in 2007 than in 1997, especially in the very elderly (75 years and older) in whom initiation was 233 days earlier [4]. Similarly, average eGFR at dialysis initiation rose from 7.9 to $8.6 \mathrm{~mL} / \mathrm{min} / 1.73 \mathrm{~m}^{2}$ between 1999 and 2003 [3]. The upward trend could be a consequence of differences in guidelines among professional societies with varying recommendations for consideration of dialysis, e.g., eGFR $<15$ or $<20 \mathrm{~mL} / \mathrm{min} / 1.73 \mathrm{~m}^{2}$ [5-7]. However, dialysis is expensive and has been shown to be associated with reduced quality of life thereby mandating clear evidence of health benefit with early commencement at higher eGFR [8]. Evidence supporting improved nutritional state or decreased risk of hospitalization or mortality attributable to early initiation of dialysis is limited and controversial [9-11].

Optimal timing of dialysis initiation remains uncertain, with some observational studies finding a lower risk of 
death with early initiation of dialysis [12-15] and others showing either a survival advantage of late dialysis initiation [3, 16-25] or comparable mortality risk between early and late initiation [26, 27]. The Initiating Dialysis Early and Late (IDEAL) study, the only randomized controlled trial to date comparing survival between early (target eGFR: 10 to $14 \mathrm{ml} / \mathrm{min}$ ) and late (target eGFR: 5 to $7 \mathrm{ml} / \mathrm{min}$ ) dialysis initiation, did not find a significant difference in mortality risk [28]. In this trial, 76\% patients in the late-start group started dialysis before the eGFR reached the target of $<7.0 \mathrm{ml}$ per minute. The mean eGFR on starting dialysis was $9.8 \mathrm{ml} / \mathrm{min}$ per $1.73 \mathrm{~m}^{2}$ in the late-start group compared with $12.0 \mathrm{ml} / \mathrm{min}$ per $1.73 \mathrm{~m}^{2}$ in the early-start group. Thus, the association between very low eGFR at initiation (ie $<7 \mathrm{ml} / \mathrm{min}$ per $1.73 \mathrm{~m}^{2}$ ) and mortality could not be assessed in that study. Furthermore, it has been reported that among patients with stage 3 CKD and initial eGFR levels $<45 \mathrm{ml} / \mathrm{min}$ per $1.73 \mathrm{~m}^{2}$, younger patients were more likely to experience an annual decline in eGFR of $>3 \mathrm{ml} / \mathrm{min}$ per $1.73 \mathrm{~m}^{2}$ than older patients [29]. However, previous studies including IDEAL did not examine if age can modify mortality risk associated with the timing of dialysis.

The purpose of this observational study was to explore the association between timing of initiation of maintenance dialysis with regard to eGFR levels at initiation and mortality risk among adult patients in Singapore. We also sought to explore whether age may affect the association between eGFR at dialysis initiation and risk of mortality in patients with ESRD. We examined these relationships after accounting for sociodemographic factors, co-morbidities, and nutritional status. Furthermore, since reduced renal function contributes directly to anemia [30] and abnormalities of bone and mineral metabolism biomarkers [31], which have been shown to be independent predictor of mortality in ESRD patients [32-35], we also explored if these biomarkers were potential mediators for any observed association between eGFR at initiation of dialysis and mortality.

\section{Methods}

\section{Population}

The data on all incident ESRD patients during January 2008 to December 2011 were obtained from the Singapore Renal Registry database, a national registry of patients with ESRD in Singapore. The Singapore Renal Registry has been shown to be comprehensive in its recording of ESRD cases since 1999. The registry defines ESRD as satisfying one or more of the following criteria: 1) serum creatinine level $\geq 5.7 \mathrm{mg} / \mathrm{dl}$, 2) eGFR $<5 \mathrm{ml} / \mathrm{min} / 1.73 \mathrm{~m}^{2}$ (based on either 4-variable modification of diet in renal disease (MDRD) Study equation, Cockcroft-Gault equation, or 24-h creatinine clearance), 3) patient underwent hemodialysis or peritoneal dialysis, 4) patient received a kidney transplant. The registry includes information on demographics, medical co-morbidities, modality of treatment and serum creatinine, as well as laboratory tests on nutritional status, anemia, and bone and mineral metabolism. The Renal Disease Registry was linked with the National Death Registry to acquire mortality information through December 2013.

Analysis inclusion criteria consisted of Singaporean citizenship or permanent residency, initiation of dialysis between January 2008 and December 2011, and age $\geq 18$ years at dialysis commencement $(n=3694)$. Patients recipients of a kidney transplant $(n=102)$ or with missing serum creatinine data $(n=327)$ were excluded. The sample size for the final analysis was 3286 patients.

They study protocol was approved by the National University of Singapore Institutional Review Board, and informed consent was waived.

\section{Measurements}

Renal function at the time of dialysis initiation was determined using CKD-EPI equation [36]. Serum Creatinine (Scr) was expressed in $\mathrm{mg} / \mathrm{dl}$ and the last recorded value before initiation was used for calculating eGFR. In this analysis, initiation of dialysis was defined as "early" if eGFR was $\geq 10 \mathrm{ml} / \mathrm{min} / 1.73 \mathrm{~m}^{2}$, "intermediate" if between 5 and $10 \mathrm{ml} / \mathrm{min} / 1.73 \mathrm{~m}^{2}$ and "late" if less than $5 \mathrm{ml} / \mathrm{min} /$ $1.73 \mathrm{~m}^{2}$.

Covariates consisted of demographic information (age, gender, education), life style (smoking), reported history of medical co-morbidities extracted from hospital medical records (diabetes, hypertension, ischemic heart disease, cerebrovascular disease, peripheral vascular disease, malignancy and liver disease), treatment modality (hemodialysis vs. peritoneal dialysis), nutritional indicators (serum albumin, body mass index (BMI)), anemia parameters (hemoglobin, transferrin saturation (TSAT) and serum ferritin) and bone and mineral metabolism parameters (serum calcium, serum phosphate and intact parathyroid hormone (iPTH)).

Outcome The primary study outcome was all-cause mortality.

\section{Data analysis}

Baseline characteristics were compared across eGFR groups using Chi-square tests for categorical variables and one-way ANOVA or Kruskal-Wallis test for continuous variables depending on whether the normality assumption was tenable.

Survival time was calculated as the elapsed time between dialysis initiation and mortality; outcomes were censored for patients alive at end of follow-up (31Dec 2013). Cox proportional hazards regression was used to investigate association between risk of mortality expressed as a hazard ratio (HR) and eGFR level at initiation of dialysis as 
reflected in the early, intermediate and late eGFR-based groups. The proportional hazard assumption was investigated using the standardized empirical score process supplemented by a Kolmogorov-type supremum test and found to be tenable. Cox regression hazard ratios were tested for significance using a chi-square test and 95\% confidence intervals (CIs) calculated. In a hierarchical analysis, covariate groups were sequentially entered into the model as follows: (1) model 1: eGFR only, (2) model 2: variable in model 1+ demographic variables (age at 1st dialysis, gender, ethnicity and education); (3) model 3: variables in model 2+ smoking, diabetes, hypertension, cerebrovascular disease, ischemic heart disease, peripheral vascular disease, malignancy, HBsAg, Anti-Hepatitis $\mathrm{C}$ status, modality at first dialysis and serum albumin. To evaluate the possible mediating effects of anemia and abnormalities of bone and mineral metabolism biomarkers on the relationship between eGFR at initiation and mortality, we further constructed model 4 including hemoglobin, serum ferritin, TSAT, serum phosphate and serum IPTH. Trend test for association between eGFR levels and risk of mortality was performed by modelling categorical eGFR as a continuous variable at each hierarchical step. Survival curves for Early, Intermediate and Late dialysis initiation (eGFR) groups were estimated using Kaplan-Meier approach and compared using the log-rank test. Adjusted survival curves based on model 3 were estimated using modified risk score procedure. The risk score is the linear proportion of Cox regression model. We calculated the median of risk scores without the contribution from categorical eGFR and then added back its effect to obtain covariate-adjusted survival functions. Tests for patient characteristics $\times$ eGRF group interactions were performed in the context of Cox model 3 to investigate potential modifiers of mortality risk associated with timing of dialysis initiation. Age was found to be the only significant modifier, hence analysis was performed stratifying on age.

The proportion of missing values for different variables ranged between 0.1 and $39 \%$.Owing to a high proportion of missing data, we also performed multiple imputation to further control for BMI and serum calcium in the models and to repeat age-stratified analysis. Because variables with missing data were either categorical or continuous and the missing data displayed an arbitrary pattern, we implemented SAS 'Proc MI' and 'Proc MIANALYZE' using fully conditional specification (FCS) method. All variables in model 4 along with BMI and serum calcium were included in the imputation model, and 20 imputed datasets were created.

$P \leq 0.05$ (2-sided test) was considered statistically significant in tests of model main effects, and $p \leq 0.10$ for interactions. Statistical analyses were performed using SAS, version 9.3 (SAS Institute, Inc., Cary, NC).

\section{Results}

A total of 3286 patients commenced maintenance dialysis during the 4-year study period with mean (SD) follow-up time of 34.7 (20.5) months. The median survival time was 65.8 months and the mortality rate was 14.2 deaths per 100 patient years (95\% confidence interval $[\mathrm{CI}], 13.5-15.0)$. The mean (SD) age was 61.5 (12.7). Median eGFR at dialysis initiation was $4.9 \mathrm{ml} / \mathrm{min}$ per $1.73 \mathrm{~m}^{2}$ with $92.7 \%$ of patients receiving haemodialysis and $6.6 \%$ initiating dialysis at eGFR $\geq 10 \mathrm{ml} / \mathrm{min}$ per $1.73 \mathrm{~m}^{2}$ (early). Compared to patients in the $5 \leq$ eGFR $<10 \mathrm{ml} / \mathrm{min}$ per $1.73 \mathrm{~m}^{2}$ (intermediate) and eGFR $<5 \mathrm{ml} / \mathrm{min}$ per $1.73 \mathrm{~m}^{2}$ (late) dialysis groups, patients in the early group were older, more likely to be male and a current smoker with more chronic diseases including diabetes, hypertension, ischemic heart disease, cerebrovascular disease and peripheral vascular disease, but were less likely to undergo hemodialysis (Table 1). Early dialysis was significantly associated with higher levels of serum albumin, hemoglobin, and serum ferritin but with lower levels of serum phosphate and iPTH (Table 1).

Kaplan-Meier analysis showed incremental improvement in survival with postponement of dialysis initiation that is reflected in the early, intermediate and late renal function groups as defined by eGFR levels (Fig. 1). Results from Cox regression models are summarized in Table 2. In univariate Cox analysis (model 1) using late initiation as the reference, the hazard ratio (HR) (95\% CI) was $2.47(2.04-2.99)$ for the early group and 1.54 (1.37-1.72) for the intermediate group, and the trend for higher hazards with earlier dialysis initiation was statistically significant $(p<0.001)$. Successive adjustment for demographic and clinical variables in models 2 and 3 attenuated the risk, but individual HRs $(1.30,95 \% \mathrm{CI}$ (1.12-1.51), $p<0.001$ for intermediate group; $1.7595 \%$ CI (1.31-2.32), $p<0.001$ for early dialysis group) as well as the trend for lower risk with later dialysis initiation $(p<0.001)$ remained statistically significant. Slight change in HRs was exhibited with additional adjustment for various biomarkers evaluating anemia and bone metabolism in model 4, but statistical significance persisted, suggesting no mediating effects of these biomarkers.

The analysis indicated significant eGFR group $\times$ age interactions in both unadjusted $(p=0.003)$ (Table 3$)$ and adjusted models (model 3, $p=0.038$ ) (Table 4). In patients younger than 65 , the significant trend persisted for higher risk of mortality with earlier dialysis initiation. However, no difference was observed among early, intermediate and late initiation groups in patients aged 65 and over. No other interactions of covariates with eGFR groups were statistically significant.

Figure 2 illustrates the adjusted survival curves (based on model 3) in the overall population and stratified by age group. The mortality risk was progressively lower 
Table 1 Baseline characteristics: All advanced CKD patients starting dialysis in Singapore in 2008-2011, by estimated glomerular filtration rate (eGFR) category at 1 dialysis

\begin{tabular}{|c|c|c|c|c|c|c|}
\hline Variables & $\begin{array}{l}\text { All } \\
(N=3286)\end{array}$ & Missing N (\%) & a Late start $(n=1709)$ & $\begin{array}{l}\text { antermediate start } \\
(n=1359)\end{array}$ & $\begin{array}{l}{ }^{a} \text { Early start } \\
(n=218)\end{array}$ & $\neq P$ value \\
\hline Age at $1^{\text {st }}$ dialysis (years, mean, SD) & & & $60.1(13.0)$ & $62.9(12.1)$ & $64.2(12.2)$ & $<0.001$ \\
\hline Age at $1^{\text {st }}$ dialysis & & & & & & $<0.001$ \\
\hline 18 to 54 years & 919 & & $568(33.2)$ & $309(22.7)$ & $42(19.3)$ & \\
\hline 55 to 64 years & 995 & & $507(29.7)$ & $427(31.4)$ & $61(28.0)$ & \\
\hline$\geq 65$ years & 1372 & & $634(37.1)$ & $623(45.8)$ & $115(52.8)$ & \\
\hline \multicolumn{7}{|l|}{ Gender } \\
\hline Male & 1862 & & $874(51.1)$ & $840(61.8)$ & $148(67.9)$ & $<0.001$ \\
\hline Ethnicities & & $28(0.9)$ & & & & 0.32 \\
\hline Chinese & 2122 & & $1097(64.6)$ & $881(65.4)$ & $144(67.6)$ & \\
\hline Malay & 873 & & $477(28.1)$ & $341(25.3)$ & $55(25.8)$ & \\
\hline Indian & 250 & & $117(6.9)$ & $119(8.8)$ & $14(6.6)$ & \\
\hline Eurasia & 13 & & $7(0.4)$ & $6(0.5)$ & $0(0.0)$ & \\
\hline Education & & $3(0.1)$ & & & & \\
\hline No/Primary & 2223 & & $1130(66.2)$ & $934(68.7)$ & $159(73.3)$ & 0.072 \\
\hline Secondary & 806 & & $443(26.0)$ & $314(23.1)$ & $49(22.6)$ & \\
\hline Post-secondary & 254 & & $134(7.9)$ & $111(8.2)$ & $9(4.2)$ & \\
\hline Smoking & & $57(1.7)$ & & & & \\
\hline Current smoker & 392 & & $203(12.0)$ & $160(12.0)$ & $29(13.7)$ & $<0.001$ \\
\hline Ex-smoker & 811 & & $368(21.8)$ & $372(28.0)$ & $71(33.5)$ & \\
\hline Never smoker & 2026 & & $1117(66.2)$ & $797(60.0)$ & $112(52.8)$ & \\
\hline BMI (mean, SD) & 2637 & $649(19.8)$ & $24.8(5.1)$ & $24.3(5.1)$ & $24.1(5.0)$ & 0.051 \\
\hline Diabetes & 2332 & & $1113(64.5)$ & $1067(78.5)$ & $162(74.3)$ & $<0.001$ \\
\hline Hypertension & 3225 & & $1676(98.1)$ & $1336(98.3)$ & $213(97.7)$ & 0.94 \\
\hline Ischemic Heart Disease & 1632 & $2(0.1)$ & $705(41.3)$ & $787(57.9)$ & $140(64.5)$ & $<0.001$ \\
\hline Cerebrovascular disease & 830 & & $367(21.5)$ & $391(28.8)$ & $72(33.0)$ & $<0.001$ \\
\hline Peripheral vascular disease & 552 & $2(0.1)$ & $214(12.5)$ & $275(20.2)$ & $63(29.2)$ & $<0.001$ \\
\hline Malignancy & 257 & $6(0.2)$ & $136(8.0)$ & $100(7.4)$ & $21(9.7)$ & 0.85 \\
\hline Hepatitis B Ag & & $142(4.3)$ & & & & \\
\hline Negative & 3032 & & 1599 (96.2) & $1240(96.5)$ & $193(98.5)$ & 0.17 \\
\hline Positive & 112 & & $64(3.8)$ & $45(3.5)$ & $3(1.5)$ & \\
\hline Anti-Hepatitis C & & $160(4.9)$ & & & & \\
\hline Negative & 3092 & & $1641(99.0)$ & $1260(98.8)$ & $191(98.5)$ & 0.41 \\
\hline Positive & 34 & & $16(1.0)$ & $15(1.2)$ & $3(1.5)$ & \\
\hline \multicolumn{7}{|l|}{$1^{\text {st }}$ dialysis modality } \\
\hline Hemodialysis & 3047 & & 1651 (96.6) & $1220(89.8)$ & $176(80.7)$ & $<0.001$ \\
\hline Peritoneal Dialysis & 239 & & $58(3.4)$ & $139(10.2)$ & $42(19.3)$ & \\
\hline Serum Albumin (g/L, mean, SD) & 2698 & $588(17.9)$ & $32.3(6.5)$ & $31.8(6.2)$ & $31.3(6.3)$ & 0.034 \\
\hline Last Hb level (g/dl, mean, SD) & 2720 & $566(17.2)$ & $10.3(1.7)$ & $10.5(1.6)$ & $10.7(1.6)$ & 0.002 \\
\hline TSAT (\%, median, IQR) & 2531 & $755(23.0)$ & $26.0(19.0-36.0)$ & $25.0(18.0-35.0)$ & $26.0(17.0-37.8)$ & 0.34 \\
\hline Serum Ferritin (ng/ml, median, IQR) & 2504 & $782(23.8)$ & $327.0(165.0-574.0)$ & $331.0(176.0-588.0)$ & $401.0(178.5-769.0)$ & 0.014 \\
\hline Serum Phosphate (mmol/L, median, IQR) & 2704 & $582(17.7)$ & $1.6(1.3-2.0)$ & $1.4(1.2-1.8)$ & $1.3(1.0-1.6)$ & $<0.001$ \\
\hline Serum iPTH (pmol/L, median, IQR) & 2453 & $833(25.3)$ & $24.3(11.6-40.7)$ & $19.8(9.8-32.7)$ & $14.4(8.3-26.3)$ & $<0.001$ \\
\hline Serum calcium (mmol/L, median, IQR) & 2004 & $1282(39.0)$ & $2.2(2.0-2.3)$ & $2.2(2.0-2.3)$ & $2.2(2.0-2.3)$ & 0.99 \\
\hline
\end{tabular}

eGFR estimated glomerular filtration rate, $\mathrm{Hb}$ Haemoglobin, TSAT Transferrin Saturation, iPTH intact Parathyroid Hormone

aLate start, eGFR $<5 \mathrm{ml} / \mathrm{min} / 1.73 \mathrm{~m}^{2}$; Intermediate start, eGFR 5-10 ml/min $/ 1.73 \mathrm{~m}^{2}$; Early start, eGFR $\geq 10 \mathrm{ml} / \mathrm{min} / 1.73 \mathrm{~m}^{2}$.

‡Continuous variables, 1-way ANOVA or Kruskal-Wallis as appropriate; categorical variables, chi-square test 


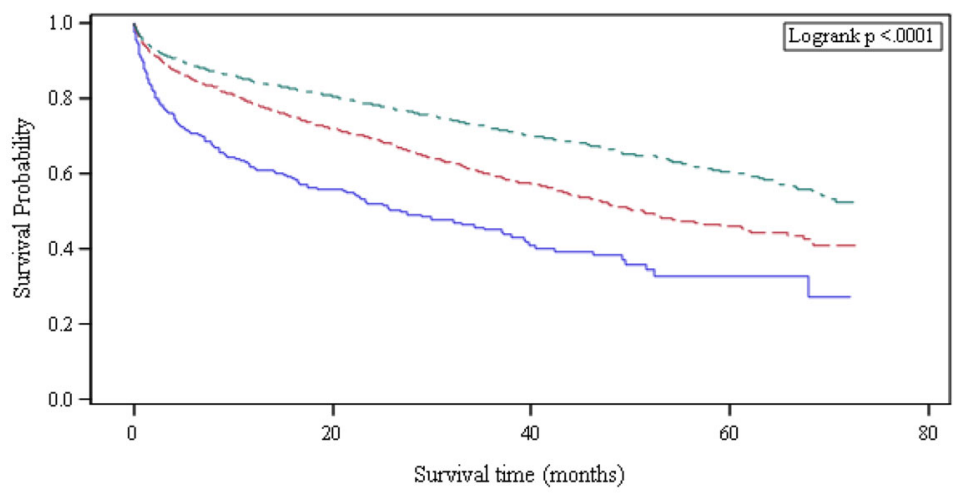

Renal function groups at dialysis initiation Eatly - - Intermediate - - Late

$\begin{array}{rrrrrr}\text { Early } & 218 & 122 & 53 & 13 & 0 \\ \text { Intermediate } & 1359 & 977 & 501 & 137 & 0 \\ \text { Late } & 1709 & 1378 & 770 & 261 & 0\end{array}$

Fig. 1 Kaplan-Meier survival curves in sub-groups based on categories of eGFR $\left(\mathrm{ml} / \mathrm{min} / 1.73 \mathrm{~m}^{2}\right.$ ) at dialysis initiation (Late, eGFR $<5$; Intermediate,5 $\leq$ eGFR $<10$; Early, eGFR $\geq 10$ )

Table 2 Unadjusted and adjusted hazard ratios (HR) associated with eGFR at initial dialysis

\begin{tabular}{|c|c|c|c|c|c|c|}
\hline${ }^{a}$ Regression model & $\begin{array}{l}\text { eGFR Category } \\
\left(\mathrm{ml} / \mathrm{min} / 1.73 \mathrm{~m}^{2}\right)\end{array}$ & $\begin{array}{l}\text { Number of overall } \\
\text { patients }\end{array}$ & $\begin{array}{l}\text { Number (incidence\%) } \\
\text { of death }\end{array}$ & HR $(95 \% \mathrm{Cl})$ & $\begin{array}{l}\text { tP value } \\
\mathrm{HR}\end{array}$ & $\begin{array}{l}t P \text { value } \\
\text { Trend }\end{array}$ \\
\hline \multicolumn{7}{|l|}{ Model 1} \\
\hline & Late $(<5)$ & 1709 & $581(34.0)$ & 1.00 & & $<0.001$ \\
\hline & Intermediate (5-10) & 1359 & $635(46.7)$ & $1.54(1.37-1.72)$ & $<0.001$ & \\
\hline & Early $(\geq 10)$ & 218 & $132(60.6)$ & $2.47(2.04-2.99)$ & $<0.001$ & \\
\hline \multicolumn{7}{|l|}{ Model 2} \\
\hline & Late $(<5)$ & 1696 & $580(34.2)$ & 1.00 & & $<0.001$ \\
\hline & Intermediate (5-10) & 1347 & $628(46.6)$ & $1.41(1.26-1.59)$ & $<0.001$ & \\
\hline & Early $(\geq 10)$ & 212 & $128(60.4)$ & $2.14(1.77-2.60)$ & $<0.001$ & \\
\hline \multirow[t]{4}{*}{ Model 3} & & & & & & $<0.001$ \\
\hline & Late $(<5)$ & 1395 & $359(25.7)$ & 1.00 & & \\
\hline & Intermediate (5-10) & 1018 & $383(37.6)$ & $1.30(1.12-1.51)$ & $<0.001$ & \\
\hline & Early $(\geq 10)$ & 127 & $61(48.0)$ & $1.75(1.31-2.32)$ & $<0.001$ & \\
\hline \multicolumn{7}{|l|}{${ }^{\mathrm{b}}$ Model 4} \\
\hline & Late $(<5)$ & 1183 & $297(25.1)$ & 1.00 & & $<0.001$ \\
\hline & Intermediate (5-10) & 867 & $315(36.3)$ & $1.23(1.04-1.46)$ & 0.015 & \\
\hline & Early $(\geq 10)$ & 98 & $46(46.9)$ & $1.91(1.38-2.65)$ & $<0.001$ & \\
\hline
\end{tabular}

Model 1: Univariate

Model 2: eGFR adjusted for age gender, ethnicity and education

Model 3: Model2+ smoking, diabetes, hypertension, cerebrovascular disease, ischemic heart disease, peripheral vascular disease, malignancy, Hepatitis B Ag,

Anti-Hepatitis $C$, modality of dialysis and albumin

Model 4: Model3+ haemoglobin, ferritin, transferrin saturation (TSAT), phosphate and intact parathyroid hormone (iPTH),

${ }^{a}$ Models employed hierarchical Cox regression analyses. $\mathrm{N}$ in models 1 to 4 varied according to missing variables in each model.

${ }^{b}$ Model 4 explored mediating effects of laboratory parameters.

$t P$ values were derived from Wald test. 
Table 3 Subgroup analysis of unadjusted hazard ratios (HR) associated with eGFR at initial dialysis by age groups

\begin{tabular}{|c|c|c|c|c|c|c|}
\hline Age group & $\begin{array}{l}\text { eGFR Category } \\
(\mathrm{ml} / \mathrm{min} / 1.73 \mathrm{~m} 2) \\
\end{array}$ & $\begin{array}{l}\text { Number of overall } \\
\text { patients }\end{array}$ & $\begin{array}{l}\text { Number (incidence\%) } \\
\text { of death }\end{array}$ & $\mathrm{HR}(95 \% \mathrm{Cl})$ & $\begin{array}{l}\text { tP value } \\
\mathrm{HR}\end{array}$ & $\begin{array}{l}\text { tP value } \\
\text { Trend } \\
\end{array}$ \\
\hline \multirow[t]{3}{*}{18 to 54 years } & Late $(<5)$ & 568 & $107(18.8)$ & 1.00 & & $<0.001$ \\
\hline & Intermediate $(5-10)$ & 309 & $103(33.3)$ & $1.96(1.50-2.57)$ & $<0.001$ & \\
\hline & Early $(\geq 10)$ & 42 & $18(42.9)$ & $2.78(1.69-4.58)$ & $<0.001$ & \\
\hline \multirow[t]{3}{*}{55 to 64 years } & Late $(<5)$ & 507 & $153(30.2)$ & 1.00 & & $<0.001$ \\
\hline & Intermediate (5-10) & 427 & $178(41.7)$ & $1.52(1.22-1.88)$ & $<0.001$ & \\
\hline & Early $(\geq 10)$ & 61 & $37(60.7)$ & $3.27(2.28-4.69)$ & $<0.001$ & \\
\hline \multirow[t]{3}{*}{$\geq 65$ years } & Late $(<5)$ & 634 & $321(50.6)$ & 1.00 & & $<0.001$ \\
\hline & Intermediate (5-10) & 623 & $354(56.8)$ & $1.21(1.04-1.41)$ & 0.014 & \\
\hline & Early $(\geq 10)$ & 115 & $77(67.0)$ & $1.67(1.30-2.14)$ & $<0.001$ & \\
\hline
\end{tabular}

$\mathrm{P}$ interaction between age and eGFR at dialysis initiation in unadjusted model was 0.0027 .

$t P$ values were derived from Wald test.

with later initiation of dialysis in the overall population (Fig. 2a) and in patients aged less than 65 (Fig. 2b and c). Differences in risk of mortality were reduced markedly among eGFR categories in patients aged 65 and above. (Fig. 2d).

Sensitivity analysis of imputed data showed consistent results after adjusting for BMI and serum calcium (Additional file 1: Table S1) or stratifying on age (Additional file 1: Table S2).

\section{Discussion}

Our study on 3286 patients starting dialysis in Singapore during 2008 to 2011 investigated association of eGFR at initiation of first dialysis with mortality. We found that early (eGFR $\geq 10 \mathrm{ml} / \mathrm{min} / 1.73 \mathrm{~m}^{2}$ ) or intermediate (eGFR 5 to $<10 \mathrm{ml} / \mathrm{min} / 1.73 \mathrm{~m}^{2}$ ) initiation of dialysis conferred significantly increased risk of mortality compared to late initiation (eGFR $<5 \mathrm{ml} / \mathrm{min}$ per $1.73 \mathrm{~m}^{2}$ ) after adjusting for effects of demographic factors, co-morbidities, modality of dialysis, and nutritional parameter. The associations did not appear to be mediated by anemia parameters and markers of bone and mineral metabolism in patients. However, this risk was modified by age, with stronger mortality risk related to early initiation in patients $<65$ years of age.

Our findings differ from the previous reports indicating improved survival with early initiation of dialysis [12-15]. However, these studies were based on selective subsets of CKD patients and did not fully account for co-morbidities therefore admitting the potential for substantial bias and confounding. Our study included all patients commencing dialysis in the comprehensive national renal registry in Singapore during the study period. We adjusted for comorbidities and several other factors and found consistent results indicating early and intermediate dialysis initiation was associated with worse survival relative to late initiation in young patients, and no better survival in the elderly patients.

Our findings are consistent with previous studies reporting similar or better survival for late dialysis initiation compared with early initiation [17, 22, 24, 25, 27, 28].

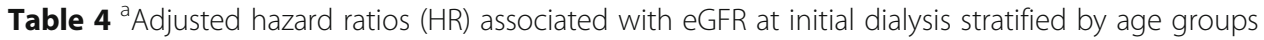

\begin{tabular}{|c|c|c|c|c|c|c|}
\hline Age group & $\begin{array}{l}\text { eGFR Category } \\
\left(\mathrm{ml} / \mathrm{min} / 1.73 \mathrm{~m}^{2}\right)\end{array}$ & $\begin{array}{l}\text { Number of overall } \\
\text { patients }\end{array}$ & $\begin{array}{l}\text { Number (incidence \%) } \\
\text { of death }\end{array}$ & HR $(95 \% \mathrm{Cl})$ & $\begin{array}{l}\neq P \text { value } \\
\mathrm{HR}\end{array}$ & $\begin{array}{l}\neq P \text { value } \\
\text { Trend }\end{array}$ \\
\hline \multirow[t]{3}{*}{18 to 54 years } & Late $(<5)$ & 495 & $69(13.9)$ & 1.00 & & \\
\hline & Intermediate (5-10) & 249 & $65(26.1)$ & $1.57(1.10-2.24)$ & 0.013 & 0.006 \\
\hline & Early $(\geq 10)$ & 28 & $9(32.1)$ & $1.95(0.95-4.03)$ & 0.070 & \\
\hline \multirow[t]{3}{*}{55 to 64 years } & Late $(<5)$ & 426 & $100(23.5)$ & 1.00 & & $<0.001$ \\
\hline & Intermediate (5-10) & 346 & $120(34.7)$ & $1.46(1.10-1.92)$ & 0.008 & \\
\hline & Early $(\geq 10)$ & 39 & $20(51.3)$ & $3.30(1.99-5.47)$ & $<0.001$ & \\
\hline \multirow[t]{3}{*}{$\geq 65$ years } & Late $(<5)$ & 474 & $190(40.1)$ & 1.00 & & 0.12 \\
\hline & Intermediate (5-10) & 423 & $198(46.8)$ & $1.12(0.91-1.39)$ & 0.29 & \\
\hline & Early $(\geq 10)$ & 60 & $32(53.3)$ & $1.36(0.90-2.04)$ & 0.14 & \\
\hline
\end{tabular}

$P$ value for interaction between eGFR and age in adjusted model was 0.038

${ }^{a}$ Adjusted for age, gender, ethnicity, education, smoking, diabetes, hypertension, cerebrovascular disease, ischemic heart disease, peripheral vascular disease, malignancy, Hepatitis B Ag, Anti-Hepatitis C, modality of dialysis, albumin.

$\neq P$ values were derived from Wald test. 

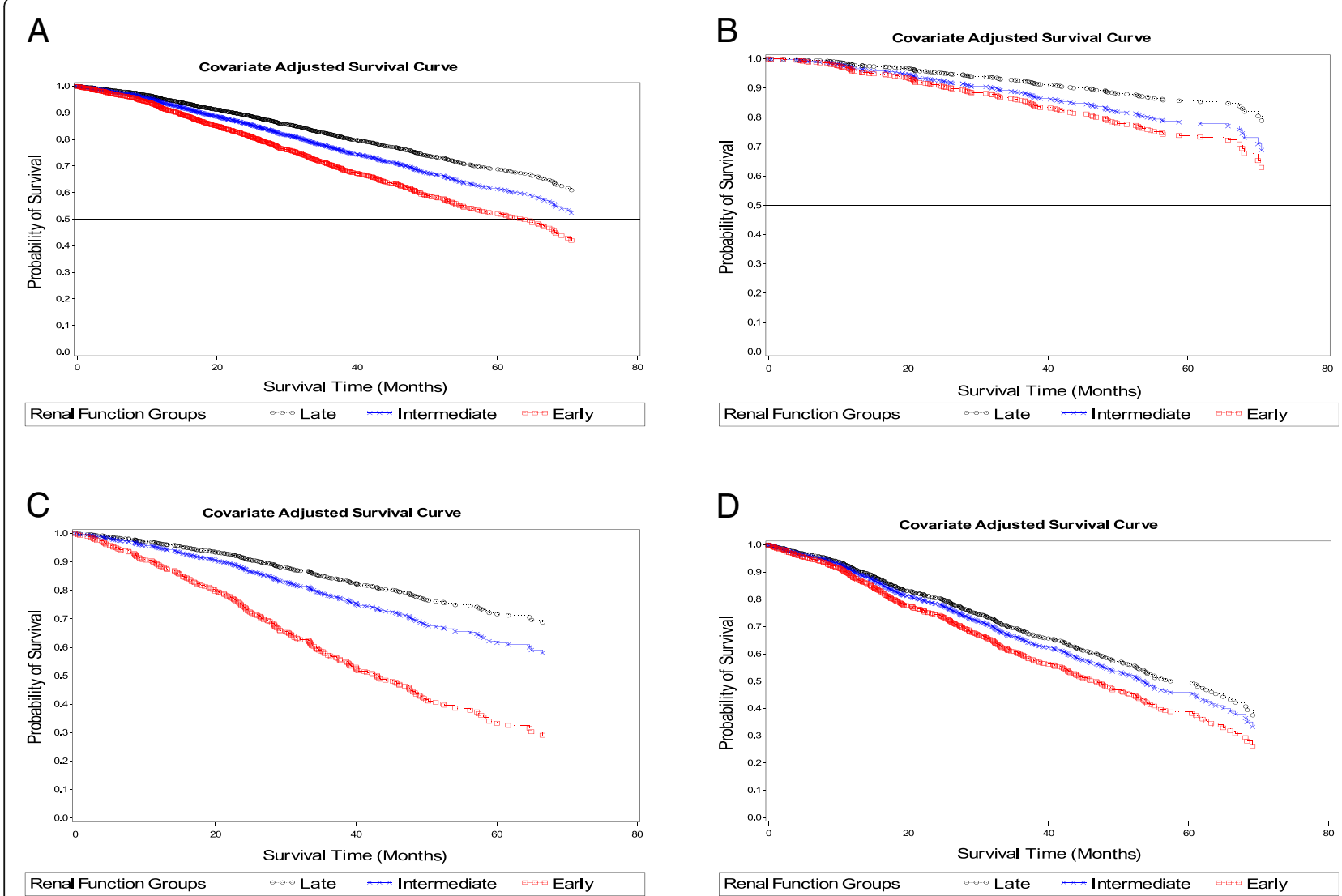

Fig. 2 a-d Overall and age-stratified Cox survival curves for eGFR $\left(\mathrm{ml} / \mathrm{min} / 1.73 \mathrm{~m}^{2}\right)$ groups at dialysis initiation. Early, eGFR $\geq 10$; Late, eGFR $<5$; Intermediate, $5 \leq$ eGFR < 10. Covariates adjusted for were age, gender, ethnicity, education, smoking, diabetes, hypertension, cerebrovascular disease, ischemic heart disease, peripheral vascular disease, malignancy, Hepatitis B Ag, Anti-Hepatitis C, modality of dialysis, albumin. a Adjusted survival curves in the whole sample. b Adjusted survival curves in patients between 18 and 54 years of age. $\mathbf{c}$ Adjusted survival curves in patients between 55 and 64 years of age. $\mathbf{d}$ Adjusted survival curves in patients aged 65 and over

In the Initiating Dialysis Early and Late (IDEAL) trial, early (10.0 to $14.0 \mathrm{ml} / \mathrm{min}$ ) vs late initiation $(5.0$ to $7.0 \mathrm{ml} / \mathrm{min}$ ) showed no difference in overall mortality between the two groups [28]. More recently, a meta-analysis of 17 studies published before 2013 concluded that higher estimated GFR was associated with greater mortality risk, independent of nutritional status [24].

Our results expand findings of previous studies by showing that dialysis initiation at higher eGFR levels increases the risk of mortality to a greater degree in younger adults $(<65$ years) [32-35]. There are several reasons why starting dialysis early may be associated with higher mortality risk. It is possible that younger patients commencing dialysis have more aggressive underlying kidney disease with more rapid loss of residual renal function. The latter has been associated with increased mortality $[37,38]$. It is also conceivable that individuals manifesting uremic symptoms or clinical indications for dialysis at higher eGFR levels have a history of rapid decline in eGFR or relative acute onset of ESRD [39]. Also, certain complications directly related to dialysis therapy such as septicemia, and cardiac and neurologic complications could be more prevalent in patients indicated for dialysis at higher eGFR levels, resulting in higher mortality rates [40]. Our findings imply that patients able to postpone commencement of dialysis to low eGFR levels have a higher probability of survival compared to those initiating dialysis early.

Several limitations merit consideration. First, similar to previous observational studies, our findings are subject to lead time bias, and indication bias. Survival time defined as the time from dialysis initiation till death would falsely amplify actual survival time for the early dialysis group because of lead time bias, resulting in an underestimation of survival advantage for later dialysis initiation. On the other hand, late dialysis initiators were more likely to be younger and less severe patients who survive to the time of starting dialysis, possibly leading to their better survival experience, namely indication bias. Moreover, deaths before declaration of ESRD status in the renal registry were 
not accounted for creating the potential of immortal time bias [41]. Despite adjustment in the models for chronic illnesses, residual confounding emains through unmeasured variables potentially influencing mortality such as acute illness, duration and quality of predialysis care, type of vascular access for dialysis, dose of dialysis, CKD aetiology, actual blood flow, C-reactive protein, or presence of uremic symptoms, and related complications. Because of these unmeasured factors, we were unable to compute mortality risk score [42] to assess the future risk of mortality for patients in different dialysis initiation groups. A second limitation is that serum creatinine measurement was not standardized. Although the CKD-EPI equation provides a better estimate of GFR and the implied risks of subsequent disease than MDRD equation, [43] it still overestimates renal function in patients with advanced CKD and low muscle mass (malnutrition), or underestimates it in patients with good nutritional status despite adjustment for BMI and serum albumin. Therefore, it is possible that the better survival experience in later starter could actually be due to a good nutrition in the presence of relatively high true GFR. Unfortunately, we did not collect 24-h urine samples to measure creatinine clearance in the study. Third, adjusted HRs were computed using only $60 \%$ of the 3592 patients $(n=2148)$ due to missing data on covariates other than serum creatinine. Compared with patients included in the final analysis, excluded patients were older and had a higher proportion of early dialysis initiators (Additional file 1: Table S3), resulting in possible underestimation of the mortality risk associated with early dialysis initiation. However, sensitivity analysis based on multiple imputation displayed consistent results.

Major strengths of our analysis are a robust national ESRD registry in a multi-ethnic population, comprehensive tracking of the mortality outcome, consistency of findings with the MDRD Study equation, and concomitant adjustment of several co-morbidities as well as a number of factors potentially associated with mortality in patients with ESRD. Thus we believe our findings are robust and widely generalizable to similar populations.

We believe our findings have important implications for clinical practice and policy related to initiation of dialysis. Internationally, the current prevalence of patients on dialysis and in need of dialysis is greatest in Asia, and the projected growth in ESRD patients is highest in Asia [1]. In agreement with IDEAL study [28], our results do not support early initiation of maintenance dialysis in the absence of any compelling clinical indication. Our findings support the 2015 update of Kidney Disease Outcomes Quality Initiative (KDOQI) guidelines for initiation of maintenance dialysis which are based on compelling indications [44].

\section{Conclusions}

In conclusion, we observed that the patients with advanced CKD who initiated dialysis early at higher levels of eGFR $\left(\geq 10 \mathrm{ml} / \mathrm{min} / 1.73 \mathrm{~m}^{2}\right)$ had increased mortality risk compared to those who initiated dialysis at intermediate levels (eGFR 5 to $<10 \mathrm{ml} / \mathrm{min} / 1.73 \mathrm{~m}^{2}$ ), with lowest risk of death among those initiating dialysis even later at eGFR $<5 \mathrm{ml} / \mathrm{min} / 1.73 \mathrm{~m}^{2}$. Anemia parameters and markers of bone and mineral metabolism did not seem to explain the observed associations. In addition, the associations were modified by age, but deserves further examination because of the small sample of older patients in the early dialysis group in this study. Our findings suggest that early commencement of dialysis offers no advantage over late dialysis, especially for younger patients in Singapore with advanced CKD, and possibly other Southeast Asian populations.

\section{Additional file}

Additional file 1: Table S1. Adjusted hazard ratios (HR) associated with eGFR at initial dialysis with further adjustment for BMI and serum calcium based on multiply imputed data. Table S2. tAdjusted hazard ratios (HR) associated with eGFR at initial dialysis stratified by age groups based on multiply imputed data. Table S3. Comparison of baseline characteristics and death between patients included and excluded from the final model. (DOC 126 kb)

\section{Abbreviations}

BMl: Body mass index; Cls: Confidence intervals; CKD: Chronic kidney disease; CKD-EPI: Chronic Kidney Disease Epidemiology Collaboration; eGFR: Estimated glomerular filtration rate; ESRD: End-stage renal disease; HR: Hazard ratio; IDEAL: The Initiating Dialysis Early and Late; IPTH: Intact Parathyroid Hormone; KDOQI: Kidney Disease Outcomes Quality Initiative; MDRD: The modification of diet in renal disease; RRT: Renal replacement therapy; Scr: Serum creatinine; TSAT: Transferrin saturation

\section{Acknowledgements}

The authors would like to express their sincere appreciation to the team from the National Registry of Diseases Office for their invaluable help and support in providing data from the Singapore Renal Registry and mortality data for this study.

\section{Funding}

None.

\section{Availability of data and materials}

The datasets generated and/or analysed during the current study are not publicly available due to the policy of Health Promotion Board in Singapore.

\section{Authors' contributions}

Research idea and study design: THJ and KYC; data acquisition: THJ and LF; Statistical analysis: LF, AZJ, JCA, and THJ. Data interpretation: LF, AZJ, JCA, KYC, and THJ; Manuscript writing: LF and THJ. All authors read and approved the final manuscript.

\section{Competing interests}

The corresponding author, Prof. Tazeen Hasan Jafar, is an editorial board member of BMC Nephrology.

Consent for publication

Not applicable. 


\section{Ethics approval and consent to participate}

The National University of Singapore Institutional Review Board approved the study protocol and waived informed consent. We obtained permission from National Registry of Diseases Office in Singapore to access data from the Singapore Renal Registry database and the National Death Registry.

\section{Publisher's Note}

Springer Nature remains neutral with regard to jurisdictional claims in published maps and institutional affiliations.

\section{Author details}

${ }^{1}$ Program in Health Services and Systems Research, Duke-NUS Medical School, 8 College Road, Singapore 169857, Singapore. ${ }^{2}$ National Registry of Diseases Office (NRDO), Health Promotion Board, Singapore, Singapore. ${ }^{3}$ Centre for Quantitative Medicine, Duke-NUS Medical School, Singapore, Singapore. ${ }^{4}$ Youth Preventive Services Division, School Health Service, Health Promotion Board, Singapore, Singapore. ${ }^{5}$ Department of Renal Medicine, Singapore General Hospital, Singapore, Singapore.

\section{Received: 24 January 2017 Accepted: 16 May 2017}

\section{Published online: 30 May 2017}

\section{References}

1. Liyanage T, Ninomiya T, Jha V, Neal B, Patrice HM, Okpechi I, et al. Worldwide access to treatment for end-stage kidney disease: a systematic review. Lancet. 2015;385(9981):1975-82.

2. U.S. Renal Data System, USRDS 2013 Annual Data Report: Atlas of chronic kidney disease and end-stage renal disease in the United States, National Institutes of Health, National Institute of Diabetes and Digestive and Kidney Diseases, Bethesda, MD,. 2013.

3. Stel VS, Dekker FW, Ansell D, Augustijn H, Casino FG, Collart F, et al. Residual renal function at the start of dialysis and clinical outcomes. Nephrol Dial Transplant. 2009;24(10):3175-82.

4. O'Hare AM, Choi Al, Boscardin WJ, Clinton WL, Zawadzki I, Hebert PL, et al. Trends in timing of initiation of chronic dialysis in the United States. Arch Intern Med. 2011;171(18):1663-9.

5. $\quad$ I.3 When to start dialysis. Nephrol Dial Transplant. 2002;17(suppl 7):10-11.

6. KDOQI. Clinical practice guidelines and clinical practice recommendations for anemia in chronic kidney disease. Am J Kidney Dis. 2006;47(5 Suppl 3):S11-145.

7. Levin A, Hemmelgarn B, Culleton B, Tobe S, McFarlane P, Ruzicka M, et al. Guidelines for the management of chronic kidney disease. CMAJ. 2008; 179(11):1154-62.

8. Da Silva-Gane M, Wellsted D, Greenshields H, Norton S, Chandna SM, Farrington K. Quality of life and survival in patients with advanced kidney failure managed conservatively or by dialysis. Clin J Am Soc Nephrol. 2012;7(12):2002-9.

9. Bonomini V, Feletti C, Scolari MP, Stefoni S. Benefits of early initiation of dialysis. Kidney Int Suppl. 1985;17:S57-9.

10. Churchill DN. An evidence-based approach to earlier initiation of dialysis. Am J Kidney Dis. 1997;30(6):899-906.

11. Obrador GT, Pereira BJ. Early referral to the nephrologist and timely initiation of renal replacement therapy: a paradigm shift in the management of patients with chronic renal failure. Am J Kidney Dis. 1998; 31(3):398-417.

12. Bonomini V, Vangelista A, Stefoni S. Early dialysis in renal substitutive programs. Kidney Int Suppl. 1978;8:S112-6.

13. Bonomini V, Feletti C, Stefoni S, Vangelista A. Early dialysis and renal transplantation. Nephron. 1986:44(4):267-71.

14. Tattersall J, Greenwood R, Farrington K. Urea kinetics and when to commence dialysis. Am J Nephrol. 1995;15(4):283-9.

15. Kim SG, Kim NH. The effect of residual renal function at the initiation of dialysis on patient survival. Korean J Intern Med. 2009;24(1):55-62.

16. Traynor JP, Simpson K, Geddes CC, Deighan CJ, Fox JG. Early initiation of dialysis fails to prolong survival in patients with end-stage renal failure. J Am Soc Nephrol. 2002;13(8):2125-32.

17. Beddhu S, Samore MH, Roberts MS, Stoddard GJ, Ramkumar N, Pappas LM et al. Impact of timing of initiation of dialysis on mortality. J Am Soc Nephrol. 2003;14(9):2305-12.

18. Kazmi WH, Gilbertson DT, Obrador GT, Guo H, Pereira BJ, Collins AJ, et al. Effect of comorbidity on the increased mortality associated with early initiation of dialysis. Am J Kidney Dis. 2005;46(5):887-96.
19. Sawhney S, Djurdjev O, Simpson K, Macleod A, Levin A. Survival and dialysis initiation: comparing British Columbia and Scotland registries. Nephrol Dial Transplant. 2009;24(10):3186-92.

20. Lassalle M, Labeeuw M, Frimat L, Villar E, Joyeux V, Couchoud C, et al. Age and comorbidity may explain the paradoxical association of an early dialysis start with poor survival. Kidney Int. 2010;77(8):700-7.

21. Wright S, Klausner D, Baird B, Williams ME, Steinman T, Tang H, et al. Timing of dialysis initiation and survival in ESRD. Clin J Am Soc Nephrol. 2010;5(10):1828-35.

22. Hwang SJ, Yang WC, Lin MY, Mau LW, Chen HC, Taiwan Society of N. Impact of the clinical conditions at dialysis initiation on mortality in incident haemodialysis patients: a national cohort study in Taiwan. Nephrol Dial Transplant. 2010;25(8):2616-24.

23. Clark WF, Na Y, Rosansky SJ, Sontrop JM, Macnab JJ, Glassock RJ, et al. Association between estimated glomerular filtration rate at initiation of dialysis and mortality. CMAJ. 2011;183(1):47-53.

24. Susantitaphong P, Altamimi S, Ashkar M, Balk EM, Stel VS, Wright S, et al. GFR at initiation of dialysis and mortality in CKD: a meta-analysis. Am J Kidney Dis. 2012;59(6):829-40.

25. Crews DC, Scialla JJ, Liu J, Guo H, Bandeen-Roche K, Ephraim PL, et al. Predialysis health, dialysis timing, and outcomes among older United States adults. Clin J Am Soc Nephrol. 2014;25(2):370-9.

26. Korevaar JC, Jansen MA, Dekker FW, Jager K, Boeschoten EW, Krediet RT, Bossuyt PM, Netherlands Cooperative Study on the Adequacy of Dialysis Study G. When to initiate dialysis: effect of proposed US guidelines on survival. Lancet. 2001;358(9287):1046-1050.

27. Yamagata K, Nakai S, Iseki K, Tsubakihara Y. Late dialysis start did not affect long-term outcome in Japanese dialysis patients: long-term prognosis from Japanese Society for [corrected] dialysis therapy registry. Ther Apher Dial. 2012;16(2):111-20.

28. Cooper BA, Branley P, Bulfone L, Collins JF, Craig JC, Fraenkel MB, et al. A randomized, controlled trial of early versus late initiation of dialysis. N Engl J Med. 2010;363(7):609-19.

29. O'Hare AM, Choi Al, Bertenthal D, Bacchetti P, Garg AX, Kaufman JS, et al. Age affects outcomes in chronic kidney disease. J Am Soc Nephrol. 2007; 18(10):2758-65.

30. Eschbach JW. Erythropoietin 1991-an overview. Am J Kidney Dis. 1991;18(4 Suppl 1):3-9.

31. Qunibi WY, Henrich Wl. Overview of chronic kidney disease-mineral and bone disorder (CKD-MBD). UpToDate Retrieved 18 Mar 2017. From https:// www.uptodate.com/contents/overview-of-chronic-kidney-disease-mineraland-bone-disorder-ckd-mbd? source=see_link.

32. Floege J, Kim J, Ireland E, Chazot C, Drueke T, de Francisco A, et al. Serum iPTH, calcium and phosphate, and the risk of mortality in a European haemodialysis population. Nephrol Dial Transplant. 2011;26(6):1948-55.

33. Wagner M, Ansell D, Kent DM, Griffith JL, Naimark D, Wanner C, et al. Predicting mortality in incident dialysis patients: an analysis of the United Kingdom renal registry. Am J Kidney Dis. 2011;57(6):894-902.

34. Koo HM, Kim CH, Doh FM, Lee MJ, Kim EJ, Han JH, et al. The relationship of initial transferrin saturation to cardiovascular parameters and outcomes in patients initiating dialysis. PLoS One. 2014;9(2):e87231.

35. Kuragano T, Matsumura O, Matsuda A, Hara T, Kiyomoto H, Murata $T$, et al. Association between hemoglobin variability, serum ferritin levels, and adverse events/mortality in maintenance hemodialysis patients. Kidney Int 2014;86(4):845-54

36. Levey AS, Stevens LA, Schmid CH, Zhang YL, Castro AF 3rd, Feldman HI, et al. A new equation to estimate glomerular filtration rate. Ann Intern Med. 2009;150(9):604-12.

37. Shafi T, Jaar BG, Plantinga LC, Fink NE, Sadler JH, Parekh RS, et al. Association of residual urine output with mortality, quality of life, and inflammation in incident hemodialysis patients: the choices for healthy outcomes in caring for end-stage renal disease (CHOICE) study. Am J Kidney Dis. 2010;56(2):348-58.

38. Obi Y, Rhee CM, Mathew AT, Shah G, Streja E, Brunelli SM, et al. Residual kidney function decline and mortality in incident Hemodialysis patients. J Am Soc Nephrol. 2016;27(12):3758-68.

39. Shlipak MG, Katz R, Kestenbaum B, Siscovick D, Fried L, Newman A, et al, Rapid decline of kidney function increases cardiovascular risk in the elderly. I Am Soc Nephrol. 2009:20(12):2625-30.

40. Inaguma D, Murata M, Tanaka A, Shinjo H. Relationship between mortality and speed of eGFR decline in the 3 months prior to dialysis initiation. Clin Exp Nephrol. 2017;21(1):159-68. 
41. Sjolander A, Nyren O, Bellocco R, Evans M. Comparing different strategies for timing of dialysis initiation through inverse probability weighting. Am J Epidemiol. 2011;174(10):1204-10.

42. Floege J, Gillespie IA, Kronenberg F, Anker SD, Gioni I, Richards S, et al. Development and validation of a predictive mortality risk score from a European hemodialysis cohort. Kidney Int. 2015;87(5):996-1008.

43. Matsushita K, Mahmoodi BK, Woodward M, Emberson JR, Jafar TH, Jee SH, et al. Comparison of risk prediction using the CKD-EPI equation and the MDRD study equation for estimated glomerular filtration rate. JAMA. 2012;307(18):1941-51.

44. https://www.kidney.org/sites/default/files/KDOQI-Clinical-Practice-GuidelineHemodialysis-Update_Public-Review-Draft-FINAL_20150204.pdf. Last Accessed 25 Jan 2017.

Submit your next manuscript to BioMed Central and we will help you at every step:

- We accept pre-submission inquiries

- Our selector tool helps you to find the most relevant journal

- We provide round the clock customer support

- Convenient online submission

- Thorough peer review

- Inclusion in PubMed and all major indexing services

- Maximum visibility for your research

Submit your manuscript at www.biomedcentral.com/submit
Biomed Central 